\title{
Pharmacovigilance Awareness among the Community Pharmacists and Pharmacy Students in the Turkish Republic of Northern Cyprus
}

Sahan Saygi ${ }^{{ }^{*}}$, Fehmi B Alkas ${ }^{1}$, Ilker Etikan ${ }^{2}$, Ilker Gelisen ${ }^{1}$ and Semra Sardas ${ }^{1,3}$

${ }^{1}$ Department of Toxicology, Faculty of Pharmacy, Near East University, Nicosia, TRNC, Cyprus

${ }^{2}$ Faculty of Medicine, Near East University, Nicosia, TRNC, Cyprus

${ }^{3}$ Department of Toxicology, Faculty of Pharmacy, Marmara University, Istanbul, Turkey

"Corresponding author: Sahan Saygi, Department of Toxicology, Faculty of Pharmacy, Near East University, Nicosia, TRNC, Cyprus, Tel: 00905338297333; Fax: 00903926802038; E-mail: sahan.saygi@neu.edu.tr

Received date: March 31, 2016; Accepted date: April 27, 2016; Published date: April 30, 2016

Copyright: (c) 2016 Saygi S, et al. This is an open-access article distributed under the terms of the Creative Commons Attribution License, which permits unrestricted use, distribution, and reproduction in any medium, provided the original author and source are credited.

\begin{abstract}
All healthcare professionals, other healthcare workers, patient caregivers, patients and even their families are all important to the healthcare system and pharmacists in every country are an important part of this system, and have a major duty to maintain and monitor the safety and efficacy of drugs as an integral part of their professional practice. Since pharmacovigilance is an indispensable part of the clinical discipline for detecting, assessing, understanding and prevention of adverse effects or any other possible drug-related problems, the knowledge of pharmacists about spontaneous reporting of adverse drug reactions is the cornerstone of pharmacovigilance for patient care and safety. On the other hand, the worldwide reporting of adverse drug reactions (ADRs) by healthcare professionals, in particular those in developing countries are with poor contribution. Therefore, the knowledge and perception of pharmacovigilance and ADR reporting of 67 community pharmacists and Near East University (NEU) Faculty of Pharmacy students on their $1^{\text {st }}(n=83)$ and $4^{\text {th }}(n=79)$ years were investigated in the Turkish Republic of Northern Cyprus (TRNC). The observed results point out that the standards of training and education need to be improved for pharmacists and undergraduates alike giving rise to the design and implementation of more effective training for drug safety.
\end{abstract}

Keywords: Pharmacovigilance; Pharmacy students; Community pharmacists

\section{Introduction}

Pharmacovigilance is the science and activities relating to the detection, assessment, understanding and prevention of adverse effects or any other possible drug-related problems [1]. Adverse Drug Reactions (ADRs) are a major problem and are one of the leading causes of mortality and morbidity [2,3]. Adverse drug reaction (ADR) is defined by WHO [4] as; any response to a drug which is noxious and unintended and occurs at doses normally used in man for prophylaxis, diagnosis or therapy of disease or the modification of physiological function.

A new medicine licensing which is also known as a marketing authorisation indicates that all the proper checks have been carried out and the benefits of a medicine are believed to outweigh the risks by the controlled and regulated clinical trials carried out in human volunteers and patients. Although clinical trials demonstrate efficacy and detect common adverse events, incidence of rare adverse events or events with significant latency cannot be reliably detected. Moreover, the length of a clinical study, standards outlining who can participate, limited number of participants disable the acquisition of important information such as; rare but serious adverse reactions, chronic toxicity, use in special groups (children, the elderly or pregnant women) and drug interactions which are often incomplete or not available. The obligation of the health care providers to report ADRs is a valuable source of information related to drug related problems [5].
Therefore, in order to achieve effective and safe pharmacological treatment, teamwork of the patient and health professionals is required [6]. Community pharmacists are the health professionals most accessible to the public and their continuous monitoring of ADRs is a requirement in almost every country. However, lack of ADR reporting by healthcare professionals in every country is a major issue that is still being frequently discussed. In a cross-sectional questionnaire-based survey conducted in Germany to assess subjective reasons for nonreporting of observed ADRs, most of the physicians stated that they report ADRs which they have observed to the competent authority rarely or never; with the majority not having reported any ADRs in 2014. However, the lack of reporting is an unfortunate worldwide situation and the most common reasons are; i) Lack of time or incentive to fill out the forms with high workload, ii) Work related stress and forgetfulness, iii) Uncertainty about causal relationship, unfamiliarity with ADR detected, iv) Lack of knowledge on how to report ADR, v) Poor knowledge about ADRs and pharmacovigilance activities, vi) Lack of knowledge and low awareness of medication errors, vii) Absence of medication safety programs in hospitals and insufficient basic medication safety training for healthcare providers, viii) Polypharmacy problem especially in polymorbid hospitalized patients to establish causality, ix) The latency period of the reaction can be too long for safety monitoring and causes failure to recognize the significance of drug-induced disease in individual patients, $x$ ) ADRs are seen as a solitary finding which is taken for granted as it may be due to the mistake of the physician or the drug is used off-label (which in itself is an adverse effect) and the health care provider does not want to get involved, no matter how benign, well-known or even significant the adverse event is, xi) fear of legal liability. These reasons for ADR non-reporting are not new, similar opinion was expressed by Inman in 
1985, who coined the valuable theoretical model of the 'seven deadly sins' of ADR underreporting by stating that while severe ADRs are unlikely to be under-reported, less severe or mild ADRs are likely to go unreported to any authority [7]. This clearly demonstrates that a lack of ADR reporting is not a problem endemic to developing countries, but can be considered to be a global problem [8]

On the other hand, 462 medicinal products have been withdrawn after approval because of serious ADRs over the course of more than 60 years. This information has been recently reported by Onakpoya et al. [9] who acquired it by searching exhaustively through scientific databases, in addition to the websites of drug regulatory authorities and textbooks.

In July 2005 Turkish Ministry of Health adopted a more systematic approach to the safety of prescription medicines and introduced new regulations for pharmacovigilance activities. In this regard, the Turkish Pharmacovigilance Center (TUFAM) aims to assess new pharmaceutical preparations for both effectiveness and safety prior to market authorization as well as during the post marketing phase [10]. Similar developments aiming to increase pharmacovigilance awareness have been started in the Turkish Republic of Northern Cyprus (TRNC), where a protocol has been signed between the Ministry of Health and Near East University (NEU) in 2008 to establish a Centre of Pharmacovigilance in order to monitor ADRs. The healthcare professionals in Northern Cyprus can, in principle, report an ADR to the Ministry of Health of the TRNC through e-mail, fax and online submission.

This study, being the first of its kind in the TRNC, aimed to produce a profile of the community pharmacists and Faculty of Pharmacy students in their $1^{\text {st }}$ and $4^{\text {th }}$ years, for evaluating the quality and sufficiency of knowledge related to pharmacovigilance.

\section{Materials and Methods}

As part of the study, 67 community pharmacists out of 188 in total from different districts of TRNC (27 from Nicosia, 19 from Famagusta, 16 from Kyrenia, 5 from Morphou) and 162 NEU Faculty of Pharmacy students ( $\mathrm{n}=83$ as $1^{\text {st }}$ year, $\mathrm{n}=79$ as $4^{\text {th }}$ year) were included in the study. All participants gave their consent to take part and completed the survey questionnaire. The questionnaire for all participants consisted of two parts: Part 1 on demographic characteristics and Part 2 on their general knowledge of pharmacovigilance. Only students of Turkish descent were included in the study and all other nationalities and ethnicities were excluded from the study as their number were relatively low and they were from a wide variety of ethnicities and localities, meaning that the determination of the level of their background on pharmacovigilance would be statistically difficult. Voluntary participation and face-to-face data collection were employed during the study. The study began in March 2015 and concluded in August 2015. Ethics approval for the study was obtained from The NEU Joint-Committee of the Research and Ethics Committee.

Data were analysed using the Statistical Package for Social Sciences (SPSS) version PASW 18.0 Chi-square tests were conducted for this purpose and ' $p$ values' $(p<0.05)$ were established to measure significant differences between responses.

\section{Results and Discussion}

Community pharmacists $(\mathrm{n}=67)$ consisted of 48 female and 19 male subjects and the mean age was 42 (range=23-68). Their work experience ranged $1-48$ years (mean $=18, \mathrm{SD}=14.8067$ ). Among them, 48 graduated from several Faculties of Pharmacy in Turkey, 7 from TRNC and 12 from the UK. Their graduation year differed between 1967 and 2015. Females made up a majority (71.6\%) of the participants. The knowledge of ADRs and pharmacovigilance did not seem to depend on their gender $(p>0.05)$. Twenty eight of the pharmacists had continued on to further education (MS, $\mathrm{PhD}$, certificate programmes) whereas 39 had no further education.

There were $162 \mathrm{NEU}$ pharmacy students, with a mean age of 22.2 years. Among the $1^{\text {st }}$ year students, there were 32 males and 51 females, $4^{\text {th }}$ year students consisted of 40 males and 39 females. The number of female responders $(55.6 \%)$ was comparatively higher than the male respondents. Overall, there were no significant differences by gender regarding the knowledge on ADR reporting and pharmacovigilance $(\mathrm{p}<0.05)$.

Questions aimed at both the community pharmacists and the students, as well as the statistical comparison between $1^{\text {st }}$ and $4^{\text {th }}$ year students, and between $4^{\text {th }}$ years and community pharmacists are shown below in Table 1 . First and $4^{\text {th }}$ year students were asked if they had heard the term of "pharmacovigilance" before, differences between their responses were not statistically significant $(p>0.05)$. Among the $1^{\text {st }}$ year students, 17 of them had pharmacists, and 27 of them had healthcare professionals in their close relatives, while $4^{\text {th }}$ year students had 15 pharmacists and 22 healthcare professional relatives. Upon analysis of the answers given by the students, there was no correlation between pharmacovigilance awareness and presence of pharmacists or healthcare professionals in their relatives ( $p>0.05)$.

In comparison, of the $4^{\text {th }}$ year students in the study $(n=79), 43$ of them $(54.4 \%)$ could not define pharmacovigilance, whereas 15 students (19.0\%) gave "reporting of adverse/side effects" as answer. Fourth year students have been found to be statistically significantly more knowledgeable about the term "pharmacovigilance" than $1^{\text {st }}$ year students $(\mathrm{p}<0.0001)$.

When the students were asked how and where they could obtain an ADR report form, only $13.1 \%(n=21)$ among the students knew how they get these forms from the correct authorities. The difference between $1^{\text {st }}$ year and $4^{\text {th }}$ year students failed to reach statistical significance $(p>0.05)$. Similarly, $13.4 \%$ of pharmacists said they knew where/how to obtain an ADR form. There is no significant difference ( $p>0.05)$ between $4^{\text {th }}$ year students and community pharmacists. The students were also asked which types of pharmaceuticals (Novel agents, OTC drugs, drugs with severe or lethal side effects, drugs requiring hospitalisation, drugs with known/expected side effects, and drugs with unknown/unexpected side effects or all of the above) ought to be subject to ADR reporting, $43.4 \%$ of 162 students gave "all of the above" as their answer. Males and females gave similar replies. First and $4^{\text {th }}$ year students gave similar replies $(p>0.05)$ whereas significantly less $(\mathrm{p}<0.0001)$ pharmacists thought that all drugs need to be subject to ADR reporting. 
Citation: Saygi S, Alkas FB, Etikan I, Gelisen I, Sardas S (2016) Pharmacovigilance Awareness among the Community Pharmacists and Pharmacy Students in the Turkish Republic of Northern Cyprus. J Pharmacovigil 4: 204. doi:10.4172/2329-6887.1000204

Page 3 of 4

\begin{tabular}{|c|c|c|c|c|c|}
\hline \multirow[b]{2}{*}{ Question } & \multirow{2}{*}{$\begin{array}{l}1^{\text {st }} \text { year } \\
\text { Students }\end{array}$} & \multirow{2}{*}{$\begin{array}{l}4^{\text {th }} \\
\text { Students }\end{array}$} & \multirow{2}{*}{ Community Pharmacists } & \multicolumn{2}{|l|}{$p$-value } \\
\hline & & & & $\begin{array}{l}1^{\text {st }} \text { and } 4^{\text {th }} \\
\text { years }\end{array}$ & $\begin{array}{l}4^{\text {th }} \quad \text { year and } \\
\text { pharmacist }\end{array}$ \\
\hline $\begin{array}{l}\text { Have you heard of the term } \\
\text { pharmacovigilance? }\end{array}$ & $17(20.8 \%)$ & $45(57.6 \%)$ & $45(67.2 \%)$ & 0.0001 & 0.168 \\
\hline $\begin{array}{l}\text { How do you define } \\
\text { "pharmacovigilance"? }\end{array}$ & $7(8.4 \%)$ & $15(19.2 \%)$ & $36(53.7 \%)$ & 0.0684 & 0.0004 \\
\hline $\begin{array}{l}\text { Do you remember courses on } \\
\text { pharmacovigilance during your } \\
\text { pharmacy education? }\end{array}$ & $5(6.1 \%)$ & $14(17.7 \%)$ & $24(35.8 \%)$ & 0.028 & 0.007 \\
\hline $\begin{array}{l}\text { Have you heard of anyone authorised } \\
\text { as "Pharmacovigilance Contact } \\
\text { Person"? }\end{array}$ & $0(0.0 \%)$ & $6(7.6 \%)$ & $4(6.0 \%)$ & 0.028 & 1 \\
\hline $\begin{array}{l}\text { Do you know where/how to obtain an } \\
\text { ADR reporting form? }\end{array}$ & $13(15.6 \%)$ & $8(10.2 \%)$ & $9(13.4 \%)$ & 0.353 & 0.609 \\
\hline $\begin{array}{l}\text { Do you remember any } \\
\text { pharmacovigilance activities being } \\
\text { conducted in the TRNC? }\end{array}$ & $1(1.2 \%)$ & $8(10.2 \%)$ & $8(11.9 \%)$ & 0.016 & 0.703 \\
\hline $\begin{array}{l}\text { Do you think all drugs should be } \\
\text { subject to ADR reporting? }\end{array}$ & $42(52.5 \%)$ & $27(34.3 \%)$ & $5(45.5 \%)$ & 0.083 & 0.0001 \\
\hline $\begin{array}{l}\text { How should you send an ADR form? } \\
\text { (Fax, Mail, Telephone) }\end{array}$ & $83(100.0 \%)$ & $79(100.0 \%)$ & $67(100.0 \%)$ & 1 & 1 \\
\hline
\end{tabular}

Table 1: Percentage of positive or correct answers given by all students and pharmacists.

In the answers related to the question of who should report ADRs, $4^{\text {th }}$ year students put significantly more emphasis on the doctor $(\mathrm{p}<0.05)$, the pharmacist $(\mathrm{p}<0.05)$, drug company $(\mathrm{p}<0.0001)$, the patient $(\mathrm{p}<0.0001)$, the nurse $(\mathrm{p}<0.0001)$ and the caretaker $(\mathrm{p}<0.0001)$ as compared to pharmacists. Students in the $1^{\text {st }}$ and $4^{\text {th }}$ year gave similar opinions on the doctor $(p>0.05)$, the pharmacist $(p>0.05)$, the drug company ( $p>0.05)$, and the nurse ( $p>0.05)$. There were significant differences in the opinions of $1^{\text {st }}$ and $4^{\text {th }}$ years concerning the patient $(\mathrm{p}<0.05)$, the caretaker $(\mathrm{p}<0.05)$. Fourth years gave a higher importance in ADR reporting to the patient and the caretaker compared to $1^{\text {st }}$ year (Figure 1). The participants' opinion was asked on the level of importance that pharmacists bear in ADR reporting. All respondents ranked pharmacists highly and all participants agreed that pharmacovigilance education should be given by Faculties of Pharmacy. The answers given by $1^{\text {st }}$ year and $4^{\text {th }}$ year students concerning the importance of the pharmacist in ADR reporting have been shown to be statistically significantly different $(p<0.05)$.

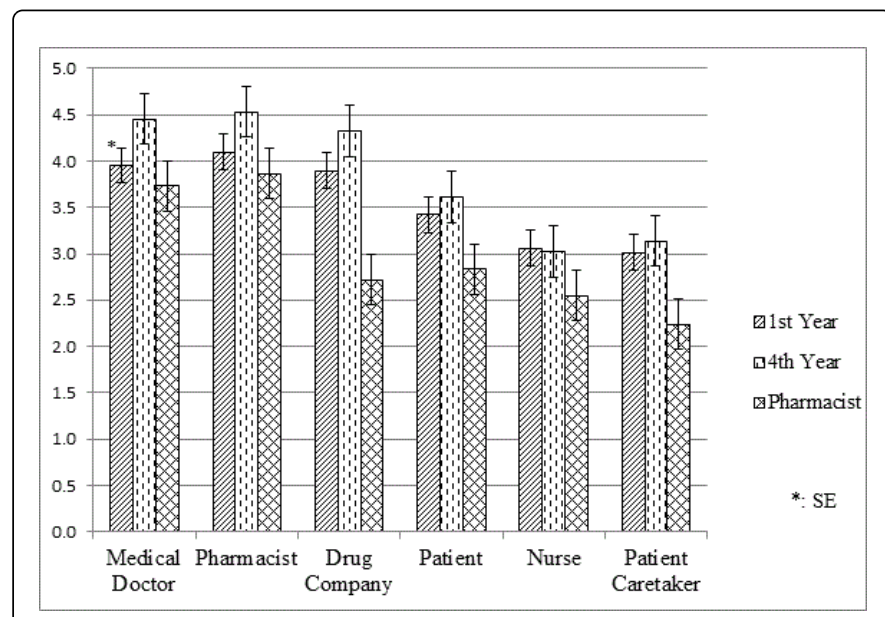

Figure 1: Who should report ADRs?

In addition to those above, additional questions were directed to gain a deeper and wider understanding of how pharmacists implement $\mathrm{ADR}$ evaluation and reporting procedures. When they were asked if they had received ADR complains in the recent years, $46.3 \%(n=31)$ responded positively. The sources of complaints were patientoriginated $(80 \%, n=24)$ whereas the remaining $20 \%(n=6)$ were sourced from patient relatives and the frequency of the ADR complaints varied from "once every 15 days" (25.0\%) to "several times a year" $(75.0 \%)$.

The pharmacists were then asked whether they relay the complaints received to any institution in the forms of an ADR report. In total, 30 
Citation: Saygi S, Alkas FB, Etikan I, Gelisen I, Sardas S (2016) Pharmacovigilance Awareness among the Community Pharmacists and Pharmacy Students in the Turkish Republic of Northern Cyprus. J Pharmacovigil 4: 204. doi:10.4172/2329-6887.1000204

Page 4 of 4

pharmacists gave a reply. The overwhelming majority $(76.7 \%, n=23)$ indicated that they do not relay these complaints to any institution, whereas only $23.3 \%(n=7)$ replied that they relay complaints to authorities. The most common reason given for non-reporting of ADRs was a perceived lack of infrastructure with similar reasons as indicated above for the lack of reporting. These pharmacists were then asked to specify the institution to which they report. $28.6 \%(n=2)$ reported to the Cyprus Turkish Pharmacists Association, whereas another $28.6 \%(n=2)$ reported to the Ministry of Health. Other replies were Drug Company $(14.3 \%, \mathrm{n}=1)$, and two unspecified others $(28.6 \%$, $\mathrm{n}=2$ ). They were further asked what classes of drugs they received complaints about most often. A total of 9 pharmacists gave a reply. The most common answer was antibiotics with $33.3 \%(n=3)$ the rest was a variety of answers including analgesics, antipyretics, oral contraceptives and OTC drugs.

Ten pharmacists reported ADRs in form; however, only 1 (10\%) pharmacist received positive feedback from the health authorities. A set of 3 questions were used to evaluate the post-graduate education of the pharmacists in the field of ADR reporting. If the pharmacists had ever received ADR reporting education in multiple forms (course, seminar, etc.) and where, a small percentage $(32.8 \%, \mathrm{n}=22)$ replied that they had received such education from Faculties of Pharmacy. When asked for their preference concerning the satisfaction of their need of education on ADR reporting, about half of them $(44.8 \%, n=30)$ indicated as seminars or conferences.

Activities to improve the understanding and awareness of pharmacovigilance have been underway in Turkey since 2008, when a similar study to our own conducted in Istanbul, Turkey indicated "an urgent need for educational programs to train them about pharmacovigilance and ADR reporting." which is a common problem faced by many countries [11-13]. The rates and attitudes towards ADR reporting, training programs should be improved for safety of public health.

In conclusion, the knowledge of pharmacy students and community pharmacists in Northern Cyprus should be enriched and enhanced on ADR reporting and pharmacovigilance. Improvement in educational programs is warranted in order to optimize patient safety and
Northern Cyprus needs to build proper infrastructure, as well as legal framework and regulatory structure as major determinants for awareness of pharmacovigilance in the future.

\section{References}

1. WHO (2002) The Importance of Pharmacovigilance. Chapter 2: 7.

2. Classen DC, Pestonik SL, Evans RS, Lioyd JF, Burke JP (1997) Adverse drug events in hospitalized patient- excess length of stay, extra cost and attributable mortality. JAMA 277: 301-306.

3. Lazarou J, Pomeranz BH, Corey PN (1998) The incidence of adverse drug reactions in hospitalized patients-a meta- analysis of prospective studies. JAMA 279: 1200-1205.

4. WHO (2002) The World Health Organization, Safety of medicines: A guide to detecting and reporting adverse drug reactions, Geneva.

5. Şardaş S, Endrenyi L, Gürsoy UK, Hutz M, Lin B, et al. (2014) A Call for Pharmacogenovigilance and Rapid Falsification in the Age of Big Data: Why not First Road Test Your Biomarker? OMICS区: A Journal of Integrative Biology 18: 663-665.

6. Furberg CD (2011) Understanding drug safety and how to maximize it for patients. Journal of the American Academy of Physician Assistants 24: 16-17.

7. Inman WH (1985) Under-reporting of adverse drug reactions. Br Med J 290: 1355.

8. Gahr M, Eller J, Connemann BJ, Schönfeldt-Lecuona C (2016) Subjective Reasons for Non-Reporting of Adverse Drug Reactions in a Sample of Physicians in Outpatient Care, Pharmacopsychiatry 49: 57-61.

9. Onakpoya IJ, Heneghan CJ, Aronson JK (2016) Post-marketing withdrawal of 462 medicinal products because of adverse drug reactions: a systematic review of the world literature. BMC Medicine 14: 10.

10. Şardaş S (2010). Pharmacogenovigilance-An idea whose time has come. Curr Pharmacogenomics Person Med 8: 1-3.

11. Toklu HZ, Uysal MK (2008) The knowledge and attitude of the Turkish community pharmacists toward pharmacovigilance in the Kadikoy district of Istanbul. Pharm World Sci 30: 556-562.

12. Hazell L, Shakir SA (2006) Under-reporting of adverse drug reactions: a systematic review. Drug Saf 29: 385-396.

13. Mirbaha F, Shalviri G, Yazdizadeh B, Gholami K, Majdzadeh R (2015) Perceived barriers to reporting adverse drug events in hospitals: a qualitative study using theoretical domains framework approach. Implementation Science 10: 110. 